\title{
THE LEGAL REGULATION OF PROTECTION OF THE RIGHTS AND INTERESTS OF THE PARTIES TO ALIMONY OBLIGATIONS
}

\author{
Gulnara S. Dzhumagazieva \\ Astrakhan State University, Astrakhan, Russian Federation
}

\begin{abstract}
Introduction: the paper analyzes the institution of alimony obligations, namely, the protection of the legal rights and interests of the parties in the event of alimony relations between them. The purpose is to determine the essence and importance of alimony obligations and protect the rights of the parties to alimony legal relations under modern family law. In this regard, the author analyzes the concept and legal nature of alimony obligations in family law of the Russian Federation, and also considers the application of legal liability measures in alimony obligations. Using the methods of scientific knowledge, the author analyzed the legal nature of alimony obligations, as well as the application of legal liability measures in this area in order to identify the ways to improve the protection of the rights and interests of the parties in the field of alimony obligations. Results: the insufficient scientific development of a number of issues related to the characterization of alimony obligations and liability of persons who violate them negatively affects the understanding of the legal nature of such liability, reduces the efficiency of its application and serves as an obstacle to further improvement of the relevant section of the family legislation. Conclusions: the analysis of the legal consolidation and practical implementation of measures of responsibility for non-performance or improper performance of alimony obligations is an essential part of the science of family law. The applicable rules of liability are regulated by a whole set of legal acts of various branches of industry, and the differentiation of such measures is implemented in different ways in modern law.

Key words: family legislation, alimony legal relations, alimony obligations, measure of legal responsibility, family members, legal rights and interests, protection of rights.

Citation. Dzhumagazieva G.S. The Legal Regulation of Protection of the Rights and Interests of the Parties to Alimony Obligations. Legal Concept = Pravovaya paradigma, 2020, vol. 19, no. 4, pp. 116-122. (in Russian). DOI: https://doi.org/10.15688/lc.jvolsu.2020.4.15
\end{abstract}

УДК 347.61 .64

Дата поступления статьи: 02.11.2020

ББК 67.404 .4

Дата принятия статьи: 25.11.2020

\section{ПРАВОВОЕ РЕГУЛИРОВАНИЕ ЗАЩИТЫ ПРАВ И ИНТЕРЕСОВ СТОРОН В АЛИМЕНТНЫХ ОБЯЗАТЕЛЬСТВАХ}

\author{
Гульнара Сарсенбаевна Джумагазиева \\ Астраханский государственный университет, г. Астрахань, Российская Федерация
}

\footnotetext{
Введение: в данной статье анализируется институт алиментных обязательств, а именно защита законных прав и интересов сторон при возникновении между ними алиментных правоотношений. Цель состоит в определении сущности и значения алиментных обязательств и защиты прав сторон алиментных правоотношений по современному семейному праву, в связи с этим автором анализируется понятие и правовая природа алиментных обязательств в семейном праве Российской Федерации, а также рассматривается применение мер юридической ответственности в алиментных обязательствах. С помощью сравнительно-правового метода познания автором в целях выявления направлений совершенствования защиты прав и интересов сторон в области алиментных обязательств была проанализирована сущность и правовая природа алиментных обязательств. Используя общенаучные методы (анализ, синтез) и специальные методы познания (формально-юридический), автор провел исследование вопроса применения мер юридической ответственности за неисполнение алиментных обязательств. Результаты: недостаточная научная разработка ряда вопросов,
} 
относящихся к характеристике алиментных обязательств и ответственности нарушающих их лиц, негативно сказывается на понимании правовой природы такой ответственности, снижает эффективность ее применения и служит препятствием для дальнейшего совершенствования соответствующего раздела семейного законодательства. Выводы: применяемые нормы ответственности в алиментных обязательствах регулируются целым комплексом нормативно-правовых актов различной отраслевой принадлежности, а дифференциация таких мер по-разному реализуется в современном праве. Наиболее результативным способом восстановления нарушенного права алиментополучателя и одновременно воздействия на неплательщика алиментов является взыскание неустойки, которая может исчисляться как законодательно, так и на договорной основе.

Ключевые слова: семейное законодательство, алиментные правоотношения, алиментные обязательства, мера юридической ответственности, члены семьи, законные права и интересы, защита прав.

Цитирование. Джумагазиева Г. С. Правовое регулирование защиты прав и интересов сторон в алиментных обязательствах // Legal Concept = Правовая парадигма. -2020 . - T. 19, № 4. - C. 116-122. DOI: https://doi.org/10.15688/lc.jvolsu.2020.4.15

\section{Введение}

Семья - главная ячейка общества, которая характеризуется добровольностью союза, общностью быта, наличием брачных отношений и стремлением к рождению и воспитанию детей. По закону Российской Федерации, семейное право ставит целью создать семейные отношения, в которых бы имели место партнерство и поддержка между каждым членом семьи. Понимать и осознавать это могут не все, поэтому заботы и материальной помощи некоторым членам семьи не хватает. Становится больше семей, где только один родитель. Неполные семьи, как правило, финансово незащищены, ведь работает в них только один человек. Страдают в первую очередь несовершеннолетние, поэтому современное семейное право, защищая интересы детей, требует сохранить алиментные обязательства.

В соответствии с законодательством Российской Федерации обязанность по выплате алиментов ложится на членов семьи на законодательном уровне. Такая поддержка оказывается нуждающимся гражданам в добровольном порядке, но при несогласии выплачивать алименты они взыскиваются с алиментоплательщика через судебные разбирательства, то есть реализация данного обязательства обеспечивается принудительной силой со стороны государства.

Сфера алиментных правоотношений является одной из главных областей современного семейного законодательства. В данный момент алиментные отношения относятся к наиболее конфликтным и поэтому заслужива- ют пристального внимания со стороны государства. Судебные разногласия в данной области семейных правоотношений всегда должны рассматриваться тщательно и всесторонне, так как от этого часто зависит обеспечение жизненных нужд и благополучие наименее социально защищенных граждан.

\section{Понятие и правовая природа} алиментных обязательств в семейном праве Российской Федерации

Россия является социальным государством. Соответствуя общественно-правовой концепции, оно обязано обеспечивать условия для достойной жизни всем своим гражданам. Не стоит забывать, что создать достойные материальные условия для жизни каждому гражданину, не имеющему достаточной социальной поддержки, непросто даже экономически устойчивому государству. В результате государство обязано ввести и узаконить требование о материальной помощи кровных родственников друг другу. Таким образом, в Семейном кодексе РФ это условие отражено, алиментные обязательства узаконены. В рамках данного законного требования члены семьи становятся морально обязанными со всеми вытекающими из этого статуса последствиями. Речь, в частности, о финансовой составляющей. Однако в процессе исполнения алиментных обязательств наступают неоднозначные ситуации, требующие уточнения и конкретного истолкования нюансов на законодательном уровне.

В переводе на русский язык слово «алименты» означает содержание. Говоря о праве 
на алименты, имеется в виду право на содержание. Право на алименты вытекает из сложившихся ранее родственных отношений. В более широком понимании право на содержание дает гражданско-правовая сделка, это договор пожизненного содержания с иждивением. Это деликт, право на возмещение вреда, полученного от потери кормильца или утраты работоспособности. Право на содержание - это и пенсии, назначаемые государством при наступлении определенных условий и являющиеся мерой социальной защиты.

Существует также различие между алиментными правоотношениями и материальным содержанием одним членом семьи другого, в том числе бывшего. Это разные события, и их нужно разделять. Алименты имеют признаки формальной определенности и являются обязательствами. Алиментное обязательство становится таковым по решению суда, утверждающего решение о принудительном взыскании или констатирующего факт добровольного принятия обязательств одной стороны по отношению к другой с помощью заключения соглашения.

Приведенные дефиниции не раскрывают порядка установления алиментных обязательств - по судебному акту или соглашению сторон, не берут во внимание факт принадлежности. Речь идет о возможности алиментных отношений между субъектами, не являющимися членами одной семьи.

Учитывая названные выше аргументы, можно дать такое толкование понятию «алименты». Средства на содержание, уплачиваемые членами семьи и иными лицами в пользу членов семей или иных лиц, определенных законом, и при наличии предусмотренных законом факторов, определенных в ходе судебного решения или добровольного соглашения.

\section{Применение мер \\ юридической ответственности в алиментных обязательствах}

Как следует из смысла обязательств по алиментным правоотношениям, установленным Семейным кодексом РФ [11], они должны обеспечить такие условия жизни несовершеннолетним детям или другим лицам, нуждающимся в материальной поддержке, кото- рые позволят получать всестороннее развитие, воспитание и образование.

Семейный кодекс РФ [11] является базой, регулирующей отношения, связанные с алиментными обязательствами. При этом используется правовой институт обязательств в области алиментных правоотношений. Алиментные обязанности регулируются не только семейным законодательством. К процессу подключаются нормы других областей права уголовного, административного, гражданскопроцессуального.

Чаще всего алиментные правоотношения устанавливаются между кровными родственниками. Традиционно являлось нормой добровольное исполнение функций по оказанию помощи близкому человеку. Однако такой подход все больше отходит на второй план в современном мире. Все больше субъектов попирают моральные устои и традиции, закрепившиеся ранее в обществе. Они слабо исполняют или вообще отказываются исполнять свои обязанности по поддержке кровных родственников. Это явление негативно отражается на всем обществе. Если у большой части подрастающего поколения недостаточно средств для всестороннего развития, общество получает недоразвитый людской ресурс, снижается его экономический и духовный потенциал. Понимая всю пагубность происходящих в сфере алиментных отношений событий, государство ужесточает ответственность за неуплату алиментов. В законы вносятся соответствующие изменения и поправки. Таким образом, изучение легального закрепления и практического осуществления мер ответственности в данной сфере является крайне актуальным.

За ненадлежащее или полное игнорирование исполнения алиментных обязанностей придется отвечать. Как считает Л.Е. Чичерова, ответственность предусмотрена законодательными актами и разделяется на имущественную, уголовную, исполнительную [13, c. 43]. С нашей точки зрения, меры ответственности можно разделить на 4 вида: семейно-правовая, гражданско-правовая, административная, уголовная.

Рассмотрим понятие ответственности в семейном праве.

В доктрине даются различные определения понятию семейно-правовой ответственнос- 
ти. По мнению А.М. Нечаевой, это наступлениенеблагоприятных последствий, отягощенных дополнительными обременениями [10, с. 168]. Нельзя сказать, что это наиболее исчерпывающее и емкое определение. Оно не ошибочно, но неполно из-за отсутствия признаков именно семейно-правовой ответственности.

Другое определение дано М.В. Антокольской. В ее интерпретации семейно-правовая ответственность есть предъявление правонарушителю дополнительных обременений различного вида или лишение его субъективного права. Данное толкование можно оценить как более глубокое и точное $[1$, с. 126].

Заметим, что семейно-правовая ответственность назначается с целью вернуть права, отнятые из-за допущенного нарушения. Следовательно, ее применение обеспечивает защиту нарушенных семейных прав.

Таким образом, для того чтобы привлечь лицо к семейно-правовой ответственности, требуется констатировать его противоправное поведение. Наличие вреда и вина правонарушителя во внимание не берутся. Причинная связь также роли не играет.

Если состав правонарушения установлен в полном объеме, в силу вступает ст. 115 СК РФ. Она требует определить ответственность нарушителя, не выполнившего условия соглашения между получателем и плательщиком алиментов. По закону, получатель алиментов имеет право требовать возмещения убытков, нанесенных невыплатой алиментов или задержкой их выплаты, но только в случае непокрытия их неустойкой.

Как решается вопрос о правовой природе указанных воззрений в юридической литературе? Некоторые авторы, в их числе Н.Ф. Звенигородская, считают меры ответственности, указанные в ст. 115 СК РФ, семейно-правовыми, поскольку они определены нормами Семейного кодекса [4, с. 113].

Такого же мнения придерживается О.Ю. Косова $[8$, с. 6], ссылаясь на норму из п. 2 ст. 115. При этом неустойка, назначаемая за неисполнение алиментной обязанности, играет роль способа обеспечения требуемого законом действия. На нормы ГК РФ в этом случае опираться вряд ли уместно.

В случае с алиментными обязательствами неустойка, являясь одним из способов обеспечения обязательств и мерой ответственности за нарушение обязательства, реализует функцию не столько штрафную, сколько восстановительно-компенсационную, поскольку стимулирующая функция неустойки в значительной степени девальвирована и алименты, рассчитанные в долях от заработка и не выплаченные вовремя, в процессе инфляции теряют свои обеспечительные функции. Именно поэтому законодатель, учитывая компенсационный характер законной неустойки, предусмотрел в п. 2 ст. 115 СК РФ санкции за неисполнение алиментных обязательств в размере $0,1 \%$ от суммы невыплаченных алиментов за каждый день просрочки. При этом сумма неустойки может быть снижена по решению суда, принимая во внимание семейное и материальное положение лица, обязанного уплачивать алименты, если неустойка несоразмерна последствиям, вытекающим из обязательств по уплате алиментов.

По нашему мнению, размер неустойки, предусмотренный семейным законодательством, не является действенным способом, побуждающим должника к надлежащему исполнению возложенных на него обязанностей. На практике очень часто встречаются случаи, когда граждане сами высчитывают размер неустойки (что не запрещено законом), не обращаясь при этом за помощью в службу судебных приставов, но проблема заключается в том, что делают они это неверно. Тем более, что временами и судебные приставыисполнители ошибаются в исчислениях неустойки. Ввиду вышесказанного представляется необходимым внесение пояснения в ст. 115 СК РФ о порядке исчисления неустойки от суммы.

Ряд специалистов уверяют [9], что нормы ст. 115 СК РФ следует отнести к категории гражданско-правовых. Это вытекает из их имущественного характера. По мнению М.В. Карпова, в алиментном соглашении могут не указываться условия ответственности [6, с. 26]. В этом случае следует ориентироваться на ст. 101 СК РФ, ее п. 1, устанавливающий гражданско-правовую ответственность за нарушение обязательств. Алиментные обязательства выражаются в денежной форме, поэтому допустимо применение нормы ст. 395 ГК РФ [2]. 
Если сравнить вышеперечисленные позиции, то более убедительным представляется мнение О.Ю. Косовой. К ее утверждению можно добавить, что, если алиментные отношения не урегулированы Семейным кодексом, допускается применение норм гражданского законодательства по аналогии.

Определение убытка дает ГК РФ. Убытки означают реальный ущерб и упущенную выгоду. В Семейном кодексе понятие не описано. Однако доктрина считает, что трактовка термина в том и другом своде законов ГК РФ и СК РФ - разная.

По мнению Е.В. Каймаковой, в семейном праве нелогично использовать термин «упущенная выгода» $[5$, с. 8]. Семейные правоотношения имеют в большей степени доверительный характер, и полученные средства не могут быть использованы для получения прибыли. По нашему мнению, по толкованию термина «убытки» в семейном праве следует понимать, что имеется в виду только упущенная выгода, а не реальный ущерб. Упущенная выгода есть средства, которые получатель алиментов потерял из-за противоправного поведения второй стороны. Однако при привлечении плательщика алиментов к семейно-правовой ответственности за алиментные правонарушения причиненный им вред не учитывается.

Что касается использования института компенсации морального вреда в семейно-правовых отношениях, в доктрине мнения на этот счет разделились. ГК РФ считает, что применение этой нормы допустимо лишь в экстренных случаях, установленных законом. Статья 30 Семейного кодекса предусматривает наступление этого вида ответственности при установлении недействительности брака. Ряд авторов высказывают мнение о необходимости внесения изменений в ст. 115 СК РФ, устанавливающих компенсацию морального вреда как меру семейно-правовой ответственности.

Проанализировав мнения ученых, можно прийти к выводу о необходимости закрепления данной меры ответственности в Семейном кодексе Российской Федерации за совершение алиментного правонарушения. Однако важно отметить, что компенсация морального вреда в семейных правоотношениях возможна только при условии исключительных обстоятельств. Например, когда для получа- теля алименты являются одним из основных источников средств к существованию, их просрочка негативно сказывается на материальном положении, или когда лицо в течение долгого времени безуспешно пыталось взыскать их с лица, уклоняющегося от выплаты алиментов или допускающего их задержку.

За злостное нарушение алиментных обязательств в отношении наследодателя, согласно ст. 1117 ГК РФ, предусмотрена гражданско-правовая ответственность в форме лишения права наследования.

Административная ответственность представляет собой меры принудительного воздействия, заключающиеся в ограничении имущественных или иных прав нарушителя либо устанавливающие для него дополнительные обязательства. Отличие административной ответственности от уголовного преступления заключается в отсутствии общественной опасности или в ее минимальном наличии.

Если семейно-правовая ответственность подразумевает восстановление материального положения получателя алиментов, то административная - преследует цель наказать нарушителя.

За неуплату средств на содержание детей или нетрудоспособных родителей предусмотрена уголовная ответственность. Меру ответственности устанавливает ст. 157 УК РФ [12]. К ответственности могут быть привлечены родители и совершеннолетние трудоспособные дети. Потерпевшими признаются несовершеннолетние дети, совершеннолетние, но нетрудоспособные дети.

В рамках декриминализации УК РФ ст. 157 попала под частичные изменения. Декриминализация, предложенная в 2015 г., ставила своей целью гуманизировать уголовное законодательство в России, так как имеющие судимость граждане испытывают в дальнейшем негативные последствия. Поправки в закон убирали эти отрицательные последствия. Кроме того, декриминализация нескольких статей УК РФ должна была уменьшить количество уголовных дел.

\section{Выводы}

Следить за выполнением алиментных обязательств сегодня помогают множество 
нормативно-правовых актов. Это Конституция [7], Семейный кодекс РФ [11], Гражданский кодекс РФ [2], Гражданско-процессуальный кодекс РФ [3], Уголовный кодекс РФ [12], указы Президента РФ, постановления Правительства РФ и др. При всем многообразии инструментов контроля права получателей алиментов нередко нарушаются, не реализуясь в полном объеме.

Семейное законодательство в области алиментных обязательств претерпевало существенные изменения последний раз более 20 лет назад. Поэтому недоработок в законодательных актах достаточно много, что сказывается на ситуации с алиментными обязательствами не лучшим образом. Экономическая ситуация в стране также ведет к необходимости постоянного изменения законов об алиментных правоотношениях.

$\mathrm{B}$ период принятия Семейного кодекса Российской Федерации заложенные в нем нормы были рассчитаны на нормальное функционирование, на условия стабильности в обществе. Но на сегодня этого нет, зато есть рост населения, нуждающегося в алиментах, и увеличение неофициальных доходов физических лиц.

\section{СПИСОК ЛИТЕРАТУРЫ}

1. Антокольская, М. В. Меры защиты и ответственности в алиментных обязательствах / М. В. Антокольская // Советское государство и право. 1990. - № 8. - С. 125-132.

2. Гражданский кодекс Российской Федерации (часть первая) от 30.11.1994 № 51-Ф3 : (ред. от 12.05.2020) // Собрание законодательства Российской Федерации. - 1994. - № 32. - Ст. 3301.

3. Гражданский процессуальный кодекс Российской Федерации от 14.11.2002 № 138-Ф3 : (ред. от 31.07.2020) // Собрание законодательства Российской Федерации. - 2002. - № 46. - Ст. 4532.

4. Звенигородская, Н. Ф. Договорные семейно-правовые санкции / Н. Ф. Звенигородская // Вестник Пермского университета. - 2013. № 2 (8), - C. 113-117.

5. Каймакова, Е. В. Защита семейных прав : автореф. дис. ... канд. юрид. наук / Каймакова Елена Васильевна. - Курск, 2011. - 25 с.

6. Карпов, М. В. О некоторых вопросах применения мер ответственности в семейно-правовых отношениях / М. В. Карпов // Семейное и жилищное право. - 2013. - № 2. - С. 24-29.
7. Конституция Российской Федерации (принята всенародным голосованием 12 дек. 1993 г.) (с поправками от 30.12.2008, 05.02.2014, 21.07.2014, 14.03.2020) // Российская газета. - 1993. - 25 дек. (№ 237).

8. Косова, О. Ю. Об ответственности за просрочку уплаты алиментов / О. Ю. Косова // Нотариyc. -2010 . - № 3. - C. 5-6.

9. Макеева, О. А. Ответственность в алиментных обязательствах - основные особенности и порядок реализации / О. А. Макеева // Семейное и жилищное право. - 2015. - № 1. - С. 17-20.

10. Нечаева, А. М. Семейное право. - 7-е изд., перераб. и доп. / А. М. Нечаева. - М. : Юрайт, 2015. $-303 \mathrm{c}$.

11. Семейный кодекс Российской Федерации от 29.12.1995 № 223-Ф3 : (ред. от 06.02.2020) // Собрание законодательства Российской Федерации. 1996. - № 1. - Ст. 16.

12. Уголовный кодекс Российской Федерации от 13.06.1996 № 63-Ф3 : (ред. от 27.10.2020) // Собрание законодательства Российской Федерации. 1996. - № 25. - Ст. 2954.

13. Чичерова, Л. Е. Ответственность в алиментных обязательствах / Л. Е. Чичерова // Юрист. 2014. - № 6. - C. 42-44.

\section{REFERENCES}

1. Antokol'skaya M.V. Mery zashchity i otvetstvennosti $\mathrm{v}$ alimentnykh obyazatel'stvakh [Measures of Protection and Responsibility in Alimony Obligations]. Sovetskoye gosudarstvo i parvo [Soviet State and Law], 1990, no. 8, pp. 125-132.

2. Grazhdanskiy kodeks Rossiyskoy Federatsii (chast' pervaya) ot 30.11.1994 № 51-FZ: (red. ot 12.05.2020) [Civil Code of the Russian Federation (Part One) dated November 30, 1994 No. 51-FZ: (as amended on May 12, 2020)]. Sobraniye zakonodatel'stva Rossiyskoy Federatsii [A Collection of Legislation of the Russian Federation], 1994, no. 32, art. 3301.

3. Grazhdanskiy protsessual'nyy kodeks Rossiyskoy Federatsii ot 14.11.2002 № 138-FZ (red. ot 31.07.2020) [The Civil Procedure Code of the Russian Federation of November 14, 2002 No. 138-FZ (as amended on July 31,2020)]. Sobraniye zakonodatel'stva Rossiyskoy Federatsii [A Collection of Legislation of the Russian Federation], 2002, no. 46, art. 4532.

4. Zvenigorodskaya N.F. Dogovornyye semeyno-pravovyye sanktsii [Contractual Family Legal Sanctions]. Vestnik Permskogo universiteta [Bulletin of Perm University], 2013, no. 2 (8), pp. 113-117.

5. Kaymakova Ye.V. Zashchita semeynykh prav: avtoref. dis. ... kand. yurid. nauk [Protection of Family Rights. Cand. jurid. sci. abs. diss.]. Kursk, 2011. 25 p. 
6. Karpov M.V. O nekotorykh voprosakh primeneniya mer otvetstvennosti $\mathrm{v}$ semeynopravovykh otnosheniyakh [On Some Issues of Application of Measures of Responsibility in Family Legal Relations]. Semeynoye i zhilishchnoye parvo [Family and Housing Law], 2013, no. 2, pp. 24-29.

7. Konstitutsiya Rossiyskoy Federatsii (prinyata vsenarodnym golosovaniyem 12 dekabrya 1993 g.) (s popravkami ot 30.12.2008, 05.02.2014, 21.07.2014, 14.03.2020) [The Constitution of the Russian Federation (adopted by popular vote on December 12, 1993) (as amended on 12/30/2008, 02/05/2014, 07/21/2014, 03/14/ 2020)]. Rossiyskaya gazeta, 1993, 25 Dec., no. 237.

8. Kosova O.Yu. Ob otvetstvennosti za prosrochku uplaty alimentov [About Responsibility for Late Payment of Alimony]. Notarius [Notary], 2010, no. 3, pp. 5-6.

9. Makeyeva O.A. Otvetstvennost' v alimentnykh obyazatel'stvakh - osnovnyye osobennosti i poryadok realizatsii [Responsibility for Alimony Obligations - The Main Features and Implementation Procedure].
Semeynoye i zhilishchnoye parvo [Family and Housing Law], 2015, no. 1, pp. 17-20.

10. Nechayeva A.M. Semeynoye pravo [Family Law]. Moscow, Yurayt Publ., 2015. 303 p.

11. Semeynyy kodeks Rossiyskoy Federatsii ot 29.12.1995 № 223-FZ: (red. ot 06.02.2020) [Family Code of the Russian Federation of December 29, 1995 No. 223-FZ: (as amended on February 6, 2020)]. Sobraniye zakonodatel'stva Rossiyskoy Federatsii [A Collection of Legislation of the Russian Federation], 1996, no 1, art. 16.

12. Ugolovnyy kodeks Rossiyskoy Federatsii ot 13.06.1996 №63-FZ(red. ot 27.10.2020) [TheCriminal Code of the Russian Federation of 13.06.1996 No. 63-FZ (as amended on 27.10.2020)]. Sobraniye zakonodatel'stva Rossiyskoy Federatsii [A Collection of Legislation of the Russian Federation], 1996, no. 25, art. 2954.

13. Chicherova L.Ye. Otvetstvennost'v alimentnykh obyazatel'stvakh [Responsibility for Alimony Obligations]. Yurist [Lawyer], 2014, no. 6, pp. 42-44.

\section{Information About the Author}

Gulnara S. Dzhumagazieva, Candidate of Sciences (Jurisprudence), Associate Professor, Department of Civil Law, Astrakhan State University, Tatishcheva St, 20A, 414056 Astrakhan, Russian Federation, gulnara.dz@mail.ru, https://orcid.org/0000-0001-7873-1493

\section{Информация об авторе}

Гульнара Сарсенбаевна Джумагазиева, кандидат юридических наук, доцент кафедры гражданского права, Астраханский государственный университет, ул. Татищева, 20A, 414056 г. Астрахань, Российская Федерация, gulnara.dz@mail.ru, https://orcid.org/0000-0001-7873-1493 